\title{
Cytogenetic Abnormalities in Carcinoma-in-situ and Dysplasias of the Uterine Cervix
}

\author{
M. M. BODDINGTON,* M.A., B.SC. ; A. I. SPRIGGS, † D.M., M.R.C.P. ; \\ MARGARET R. WOLFENDALE, $\ddagger$ M.B., B.S.
}

[With Special Plate]

In view of the striking chromosomal abnormalities found in the cells of human carcinoma, it is of the greatest interest to know at what stage they arise. Data concerning the chromosomes of precancerous lesions are very few, and some observations are presented in this paper.

In a preliminary note (Spriggs, Boddington, and Clarke, 1962a) certain cytogenetic abnormalities were described in the cells of carcinoma-in-situ of the cervix uteri examined in direct squashes, and none had the pattern expected for normal human tissues. Owing to technical difficulties it was not possible to present satisfactory photographic karyotype arrays. A different technique has now been applied, and a much closer examination has been made of the type of anomaly present. The cells examined were in mitosis at the time the specimen was collected, and any abnormalities found are presumed to have arisen in vivo.

\section{Material and Methods}

Biopsies were carried out on patients with suspicious cervical smears. Of nine cases, seven had cervical cone biopsies, one had a hysterectomy, and one (Case 1) a simple biopsy of the vaginal wall. The major part of the biopsy specimen was handled in the usual way for histological diagnosis, but a segment about $3 \mathrm{~mm}$. broad was cut from it (the site from which it came being noted), and this fragment was used for the cytogenetic studies. (In correlating this piece with the corresponding histological sections, it is inevitable that some error must occur, because the histological appearances may differ on the two sides of the piece taken. It can be assumed that the dividing cells whose chromosomes are being studied come from an area with a high mitotic rate, or they would not have been found at all ; so that in cases of doubt where more than one type of epithelium may be represented in the sample it is probable that our cells come from that which is most actively dividing.)

The piece of tissue, shaped like the segment of an orange, was held by forceps in $5 \mathrm{ml}$. of tissue culture medium 199 (Glaxo) containing 1 part per million of colchicine, and the surface was scraped with a scalpel. When all the epithelium had been removed, the piece of solid fibrous tissue was discarded. The cell suspension was incubated for one hour at $37^{\circ} \mathrm{C}$. It was then centrifuged and the cell deposit resuspended in $0.9 \%$ sodium citrate solution. This suspension was incubated for 10 minutes at $37^{\circ} \mathrm{C}$. The cells were then fixed as follows: to $4.5 \mathrm{ml}$. of the suspension $0.5 \mathrm{ml}$. of $50 \%$ acetic acid was added and mixed; after five minutes $5 \mathrm{ml}$. of $60 \%$ ethyl alcohol was added and mixed; after a varying interval, usually about five minutes, the mixture was centrifuged and the supernatant replaced with $30 \%$ alcohol. This suspension was stored overnight and, if necessary, for several days. * Scientific Officer, Cytodiagnostic Unit, Churchill Hospital, Oxford. † Clinical Cytologist, Stoke Mandeville Hospital, Aylesbury.
Squashes were prepared as follows. The alcohol suspension was centrifuged to deposit the cells and the supernatant fluid replaced with $50 \%$ acetic acid to give a suspension of cells and small fragments, the correct density of which was found out by experience. For each preparation a drop was pipetted out on to a clean glass slide and covered with a vinyl coverslip. (These coverslips are made from adhesive vinyl tape by backing the adhesive side with thin paper and cutting into squares.) The specimen was squashed by firm pressure with the thumb. The slide was then placed upright in a bath of $10 \%$ acetic acid, and in a few seconds the coverslip floated off. The slide was immediately removed and left to dry in air. Staining was done with acetic orcein, and the preparations were mounted and stored for later examination.

\section{Counting}

All chromosome counts were performed by either A.I.S. or M.M.B. Bias was avoided by dividing a diagram of each metaphase with pencil lines, and scoring the different areas separately ; they were then added up to give the total count.

Any cell was used in which the chromosomes were distinct enough for a count to be done without guesswork. This does not mean that all counts were exact. In many cases a judgment had to be made whether a given configuration represented one chromosome or two. Decisions of this kind were made in the light of reason and experience, but with material of this quality they have not always been found precisely repeatable at a later recount. Broken cells were included if it seemed likely that all the chromosomes were present, but metaphases which were obviously scattered or fragmentary were not used.

\section{Biopsy Results}

The series comprises nine cases. All the biopsies showed lesions of the kind which are known to carry a high risk of developing into carcinoma-that is, severe dysplasias and carcinoma-in-situ. One involved the vagina (Case 1) and the others the cervix uteri. In Case 1 a subsequent biopsy of the vagina at a distance from the first showed invasive carcinoma ; in the other cases no evidence of invasion could be found.

In the same period of time 15 other cases with the same kind of epithelial abnormalities were processed, with unsatisfactory results ; either no cells in mitosis were found or the chromosomes were not well enough displayed for counting or analysis.

We have not tried to define carcinoma-in-situ. The definition recommended by the International Committee on Histological Terminology for Lesions of the Uterine Cervix (1961) begins by excluding cases in which the epithelium differentiates towards its surface, but adds a rider cancelling this. As the lesions are all different we have avoided the semantic issue altogether in cases where there might be differences of opinion. 


\section{Case 1}

A woman aged 50, three and a half years past the menopause, with one child, had a brown vaginal discharge. A vaginal smear showed many cells with enlarged nuclei, and a biopsy specimen was taken from the left lateral wall of the vagina on 18 March 1963. This showed abnormal thickened epithelium, with some differentiation towards the surface but interpreted as intraepithelial carcinoma. On 26 March a vagino-hysterectomy was performed, and, besides a very extensive intraepithelial lesion of the type already mentioned, a small invasive carcinoma was found about $2 \mathrm{~cm}$. away from the biopsy site.

Chromosome studies were performed in the first place on a fragment from the biopsy specimen (No. 1). Pieces were also taken from the operation specimen, but these provided less successful preparations and only a few counts could be performed; these samples were from the posterior wall low down (No. 2) and from the left anterior quadrant of the cervix (No. 3).

As is shown in Fig. I, the biopsy showed a wide scatter of counts, including many below 35 . This is taken to be evidence of cell

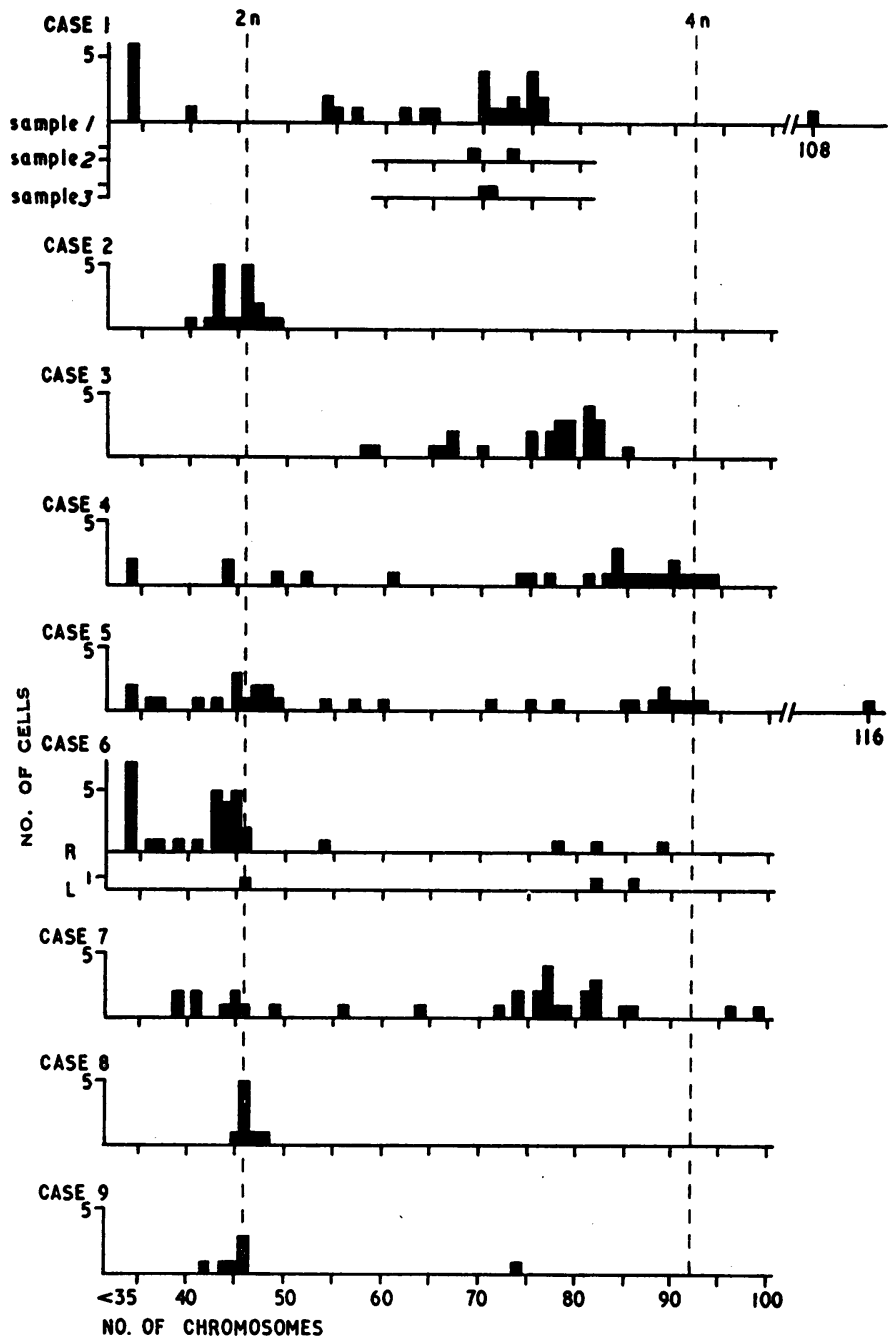

FIG. I.-Histograms from the nine cases, showing distribution of chromosome counts.

breakage. However, there is a very distinct aggregation of counts between 70 and 76, which can safely be assumed to represent an abnormal clone. The distribution of chromosomes in the conventional groups is very abnormal, but none show clear evidence of morphological aberration. Fig. II shows a karyotype array of one of the cells from sample No. 1, with 76 chromosomes. $^{1}$

In the specimen obtained at operation, it was hoped to obtain evidence of clonal development by examining samples from different sites. Only two sites produced metaphases which could be counted,

${ }^{1}$ The uncut cell is shown in Fig. 4 of Spriggs (1964). and these not with certainty. A piece near the lower end of the vagina gave two counts of 69 and 73 respectively, and the other taken from the cervix uteri gave counts of 70 and 71 (both these areas were involved by the lesion). These cells could not be karyotyped, but as both samples gave counts in the same range as before it is very likely that the whole of the involved epithelium was derived from the same clone of abnormal cells. No sample was taken from the point subsequently shown to have invasive carcinoma, as this area was not distinguishable by the naked eye.

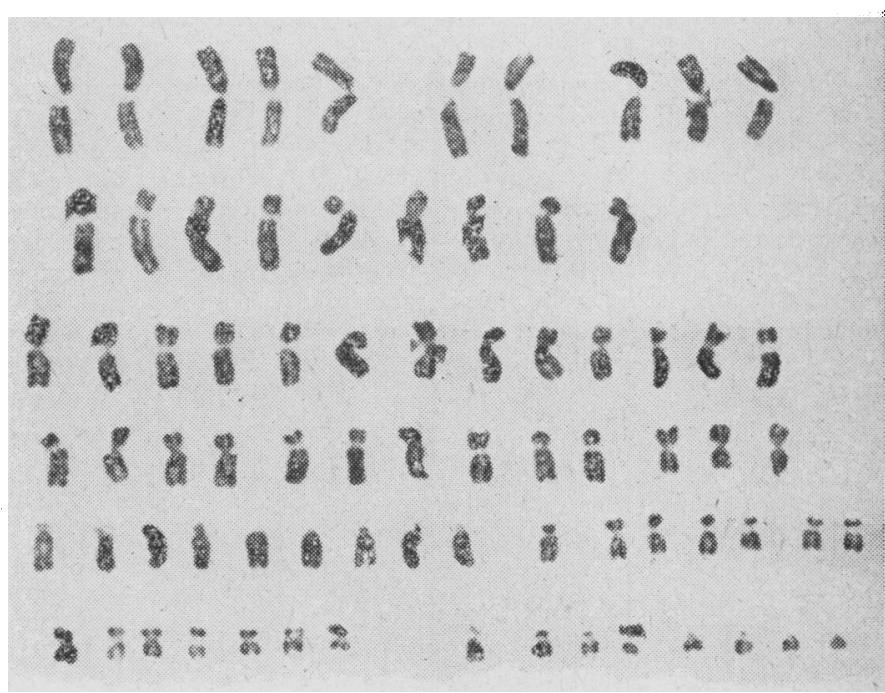

FIG. II.-Case 1. Karyotype of a cell with 76 chromosomes, from the original biopsy (sample No. 1). Intraepithelial carcinoma associated with a small invasive growth of the vagina.

\section{Case 2}

A 3-parous woman aged 34 was found at post-natal examination to have an abnormal cervical smear. A cone biopsy of the cervix was performed on 8 February 1963, and the sections showed carcinoma-in-situ.

The chromosome counts are shown in Fig. I. There were distinct peaks at 43 and 46 . Photographic karyotypes could be performed on only two cells. One of them had 45 chromosomes, in which there appeared to be the following anomalies: an extra $\mathbf{A}$ group chromosome, one missing chromosome in each of the $\mathrm{D}$ and $\mathrm{E}$ groups, two missing in the $F$ group, and two extra $G$ group chromosomes.

The other cell had 46 chromosomes. It appeared to have an extra No. 3 chromosome, and one $\mathrm{F}$ group chromosome was missing. These two cells were different, and although chromosome morphology was distorted it seemed impossible to rearrange either of them to make a normal set.

\section{Case 3}

A woman aged 32 , with two children, came for advice on account of menorrhagia. The cervical smear was suspicious, and a cone biopsy of the cervix was performed on 18 July 1963 . This showed areas of low atypical epithelium with numerous mitoses adjacent to both of the pieces studied for chromosomes.

Chromosome preparations made from the anterior lip of the cervix showed a scatter of counts from 58 to 85 , with a concentration of values around 79 (Fig. I). This is evidence of new clone formation, because no counts were found in the neighbourhood of 46 or 92 . In one karyotyped cell with 75 chromosomes, chromosome morphology was not definitely altered, but the distribution in Patau's groups was far from what would be expected if there had been random loss by breakage of a tetraploid cell. For instance, there were 14 probable D group chromosomes (13-15), and only four in the G group (21-22).

A sample was taken at the same time from the posterior lip of the cervix, but it showed very few mitoses. All the metaphases studied had about 46 chromosomes, but they were not considered satisfactory for counting. 


\section{Case 4}

A woman of 29 with polymenorrhagia and a clinically normal cervix was found in 1960 to have abnormal cells in her cervical smear. She had had one child. A biopsy specimen taken on 19 July 1960 showed chronic cervicitis only. In March 1963 she had a large cervical erosion and a suspicious cervical smear, and a cone biopsy was therefore performed on 26 August 1963. This showed some areas with complete loss of stratification of the squamous epithelial cells, but most parts (including the area sampled) showed distinct basal and differentiating layers although with abnormal nuclei (Special Plate, Fig. 1).

The chromosome preparations gave a wide scatter of counts, and there was no well-defined modal value (Fig. I). There was, however, some aggregation of counts in the 80-95 region. Figs. III and IV show a cell with a chromosome count of 49 . It deviates in several respects from the normal. In the $A$ group there are four metacentrics and one submetacentric. In the $B$ group there is perhaps an unusual disparity between the lengths of the long arms of 4 and 5. There is an extra chromosome in the $\mathrm{C}$ group, two extra ones in the $F$ group, and the $G$ group contains one extra member. Unfortunately, no other fully analysable cells could be found for comparison.

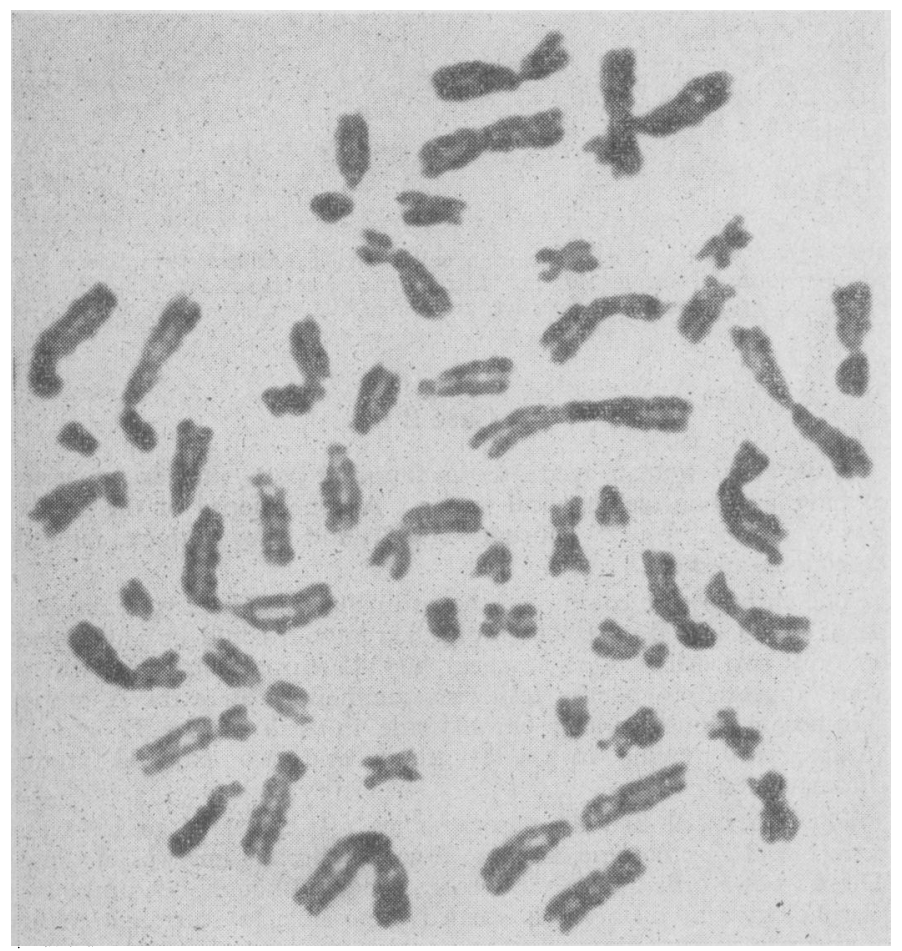

Fig. III.-Case 4. Dividing cell with 49 chromosomes, from anterior cervical lip.

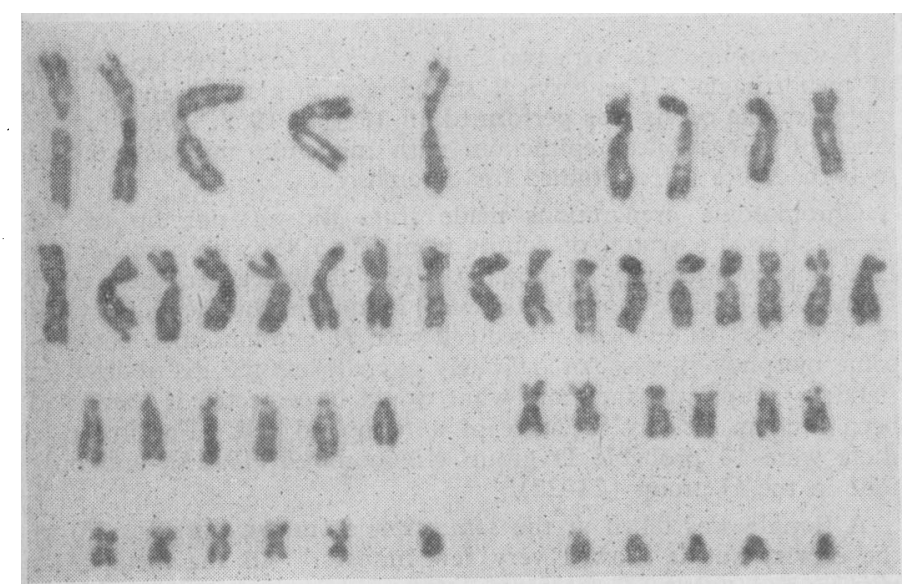

Fig. IV.-Case 4. The 49 chromosomes of Fig. III arranged as a karyotype.
A woman (8-para) aged 37 was found to have a suspicious cervical smear when 16 weeks pregnant in May 1962. This persisted later in pregnancy, and still showed many abnormal cells in July.

A hysterectomy was performed on 13 September 1963, and the cervix was found to contain a small area of carcinoma-in-situ on the anterior lip.

The chromosome counts showed a wide scatter, with a number of presumably broken cells with low counts. Fig. I shows a cluster of counts at 45 and just above, and there is a smaller group in the region of 90 . In view of possible inaccuracies in counting, these values might be suspected to represent normal diploid and tetraploid. The quality of the preparations did not permit of photographic karyotyping.

\section{Case 6}

A woman aged 36 suffered from dysmenorrhoea. She had a suspicious cervical smear, and accordingly a cone biopsy of the cervix was performed on 18 November 1963. This showed areas of very atypical epithelium of the carcinoma-in-situ type. Pieces were taken from the right and left sides for chromosome studies, both from areas involved by the lesion. Numerous mitoses were found on the right, but they were scarce in the left-hand piece. The counts are shown in Fig. I.

On the right, most of the counts fell between 43 and 46 , the most frequent scores being 43,44 , and 45 . A number of fragmented metaphases with counts below 35 were also found. There were three counts in the range 78-89. On the left, only three counts were obtained-46,82, and 86. A photographic karyotype was prepared from a cell from the right side with 44 chromosomes, and this could not be interpreted as a normal diploid with two chromosomes missing. It lacked two from the D group, one from the $\mathrm{E}$ group, and one from the $\mathrm{F}$ group. The larger chromosomes were difficult to classify owing to distortion, but there were certainly two extra in the A-C groups taken together.

\section{Case 7}

A woman aged 34, with two children, was referred in 1962 with irregular periods, intermenstrual bleeding, and abdominal pain. Examination revealed leucoplakia on the anterior lip of the cervix, and a cervical smear showed some abnormal cells. A biopsy of the leucoplakic area showed only hyperkeratosis and parakeratosis. Cervical smears remained abnormal, and in December 1963 there were numerous cells suspicious of malignancy. A cone biopsy was therefore performed on 1 January 1964, and this showed the appearance illustrated in Fig. 2 '(Special Plate). Chromosome preparations showed frequent cells in mitosis, though only one was of good enough quality to allow karyotype analysis. A characteristic field is shown in Fig. 3 (Special Plate). Thirty-one counts were performed, and these mainly fell into two groups-a larger one between 72 and 86, and a smaller one below diploid (Fig. I). The larger group shows two peaks, at 77 and 82 .

A cut-out karyotype of a cell with 46 chromosomes showed 8 chromosomes in the A group, 14 in the $\mathrm{C}$ group, only two in the $F$ group, and six in the $G$ group. Although the chromatids were closely apposed and a few chromosomes could be differently classified, this could not be interpreted as a normal cell.

\section{Case 8}

A 25-year-old woman with one child was examined in January 1964 on account of intermenstrual bleeding. Clinical examination showed a simple erosion. Cervical smears contained abnormal cells, and a cone biopsy was therefore performed on 3 February 1964. Two slices were taken for chromosome study, only one of which showed mitoses. The cone showed a variety of abnormal appearances in different areas; those from the posterior lip corresponding to the piece used for cytogenetic studies showed dysplasia only, but in other areas there were changes interpreted as probable carcinomain-situ.

Eight cells were scored and five of them had 46 chromosomes. Four cells were considered good enough to use for photographic karyotypes. One cell appeared to be normal. Another cell 


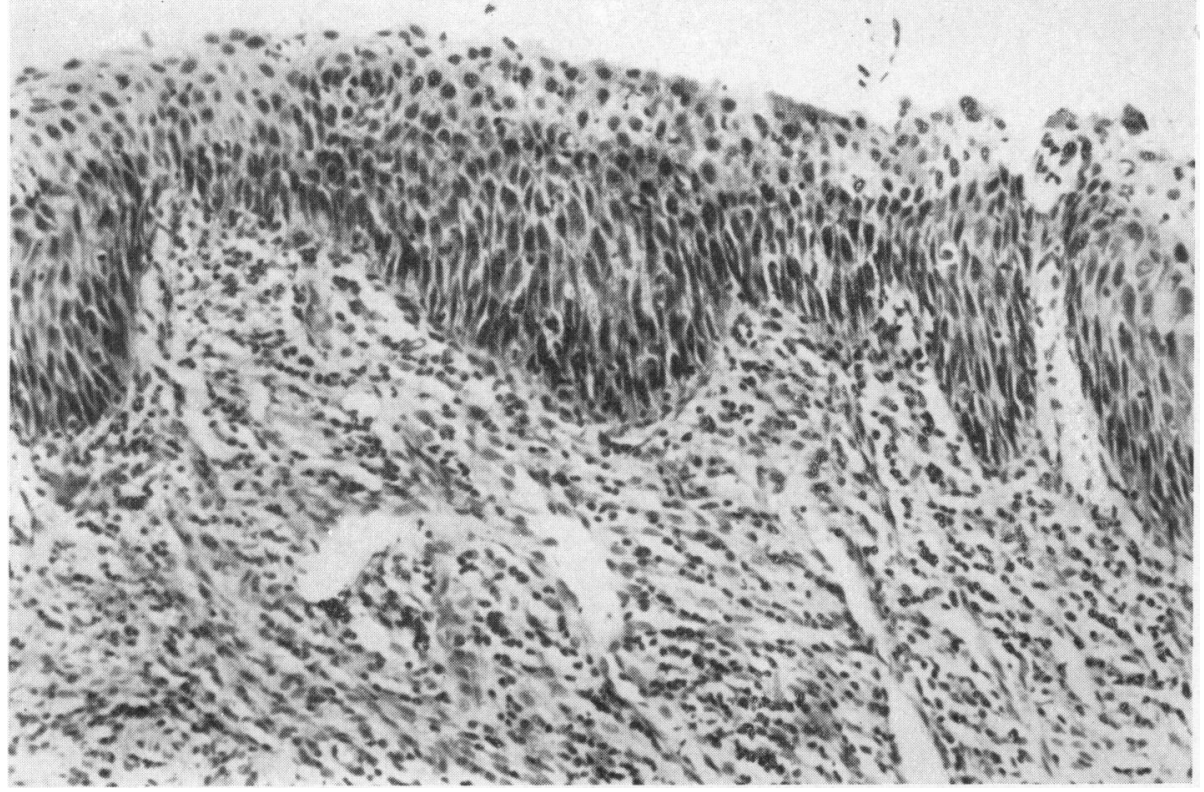

Fig. 1.-Case 4. Section from anterior lip of cervix uteri. The epithelium has abnormal enlarged nuclei in the superficial layers. ( $H$. and $E$. $\times$ 180.)

FIG. 2.-Case 7. Section from biopsy of cervix showing abnormal polarity and loss of epithelial differentiation. $(\mathrm{H}$. and E. $\times 210$.)
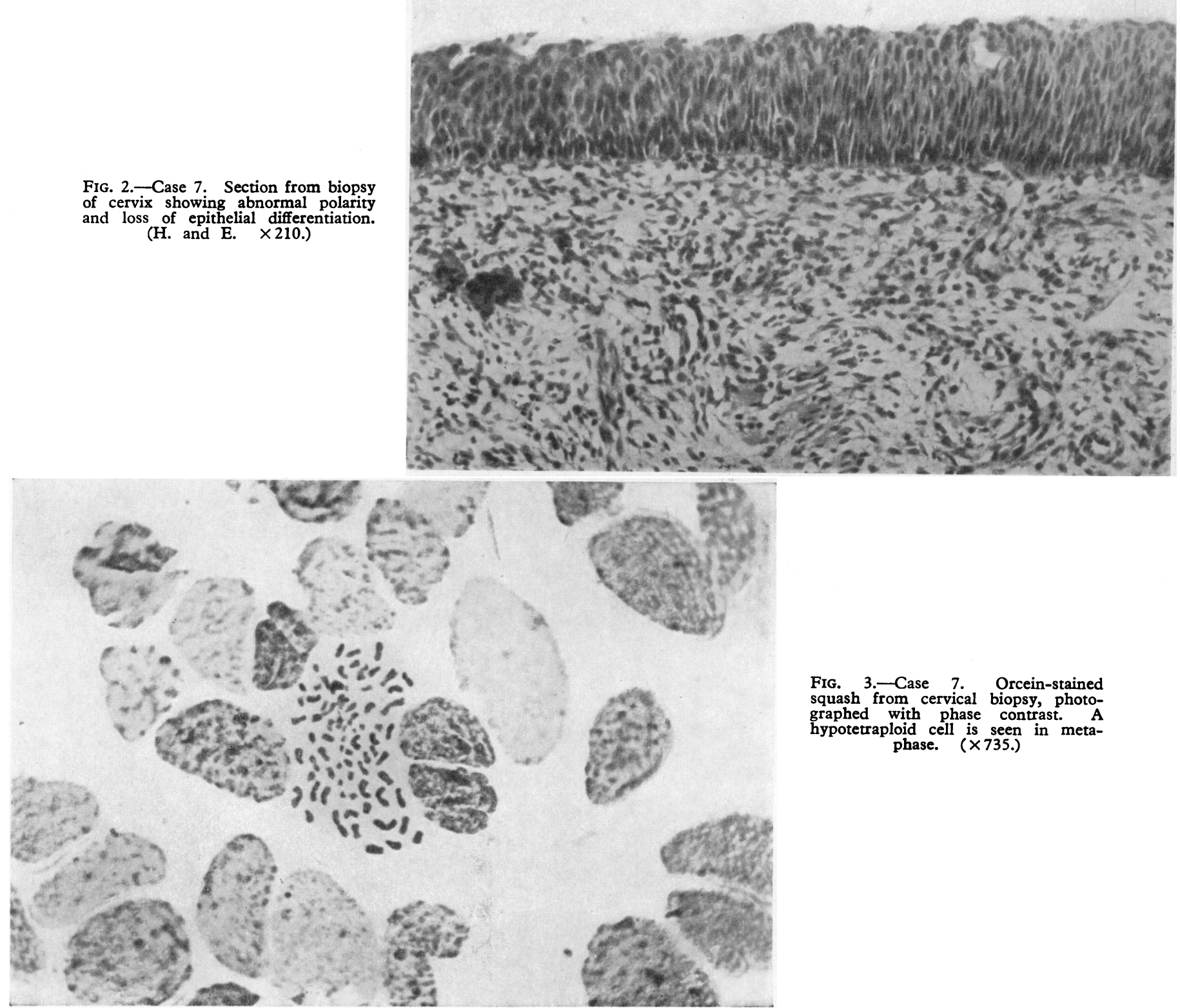

FIG. 3.- Case 7. Orcein-stained squash from cervical biopsy, photographed with phase contrast. A hypotetraploid cell is seen in metaphase. $(\times 735$. 
M. M. BODDINGTON ET $A L$ : CYTOGENETIC ABNORMALITIES IN CARCINOMA-IN-SITU

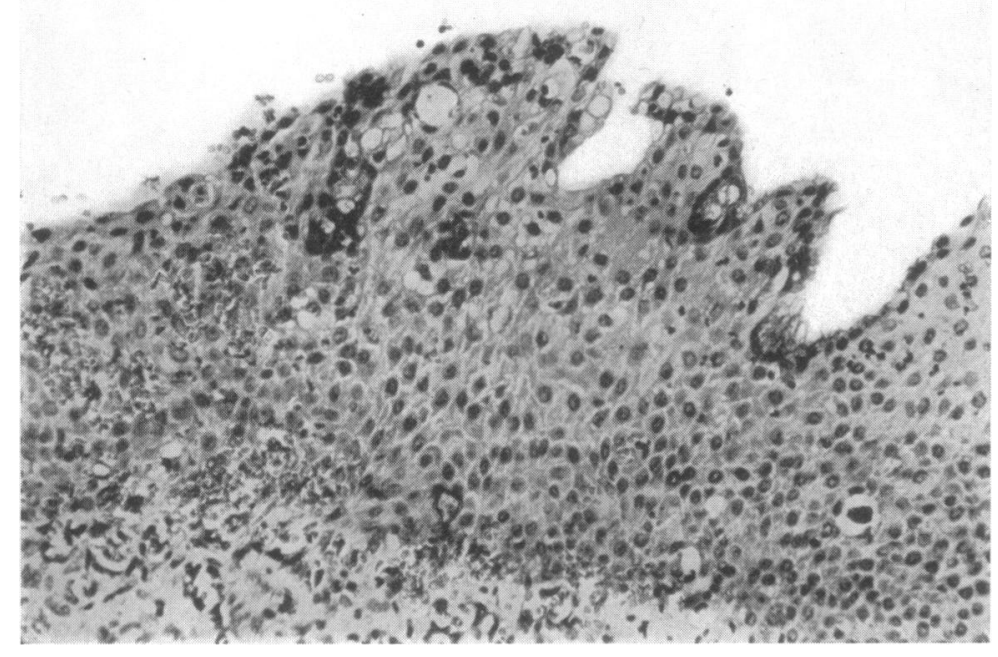

FIG. 4.-Case 9. Section from the posterior lip of the cervix uteri, adjacent to the piece taken for chromosome study.

(H. and E. $\times 175$.)

W. A. SOUTER: BOLUS OBSTRUCTION OF GUT AFTER USE OF LAXATIVES

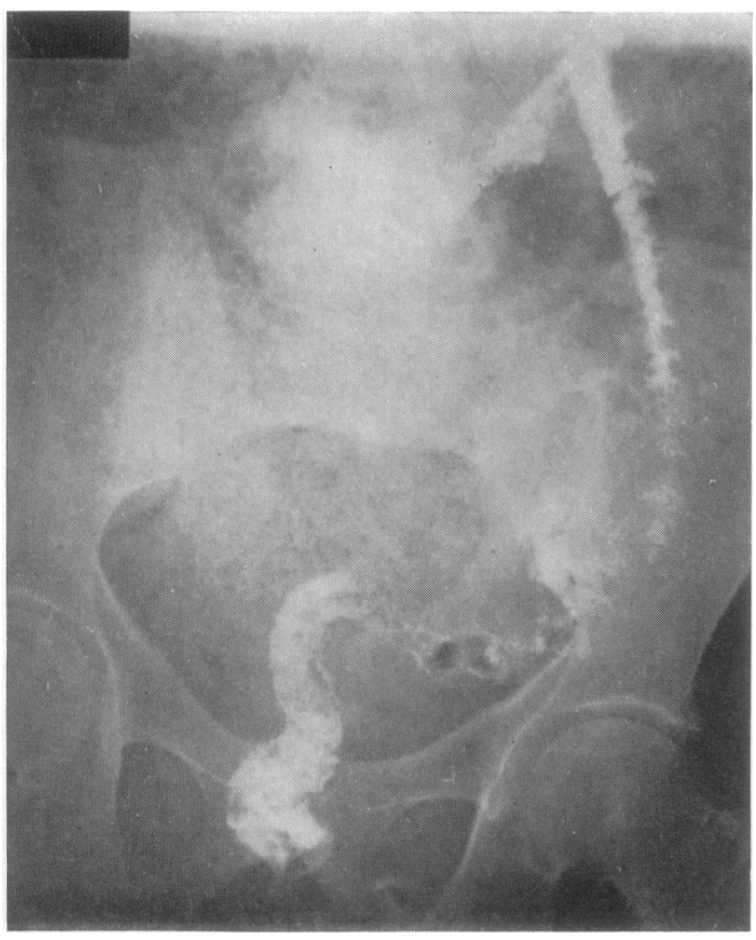

FIG. 1

FIG. 1.-Case 1. Radiograph of abdomen showing immense faecal distension of caecum, ascending colon, and hepatic flexure. The collapsed bowel distal to the colostomy has been outlined by barium for comparison.

FIg. 2.-Case 2. Radiograph showing faecal distension of hepatic flexure.

FIG. 3.-Case 3. Radiograph of abdomen showing multiple fluid levels throughout small bowel together with marked faeculent distension of caccum and ascending colon.

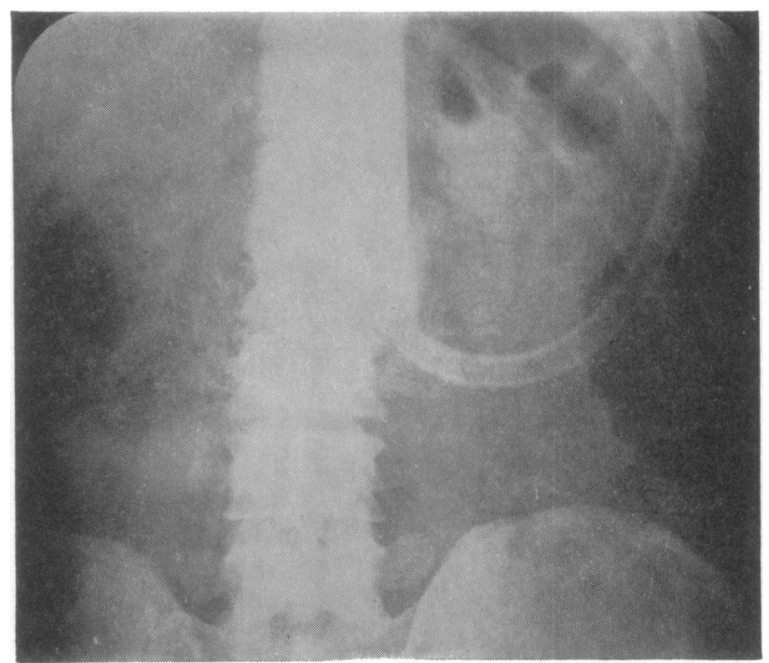

FIG. 2

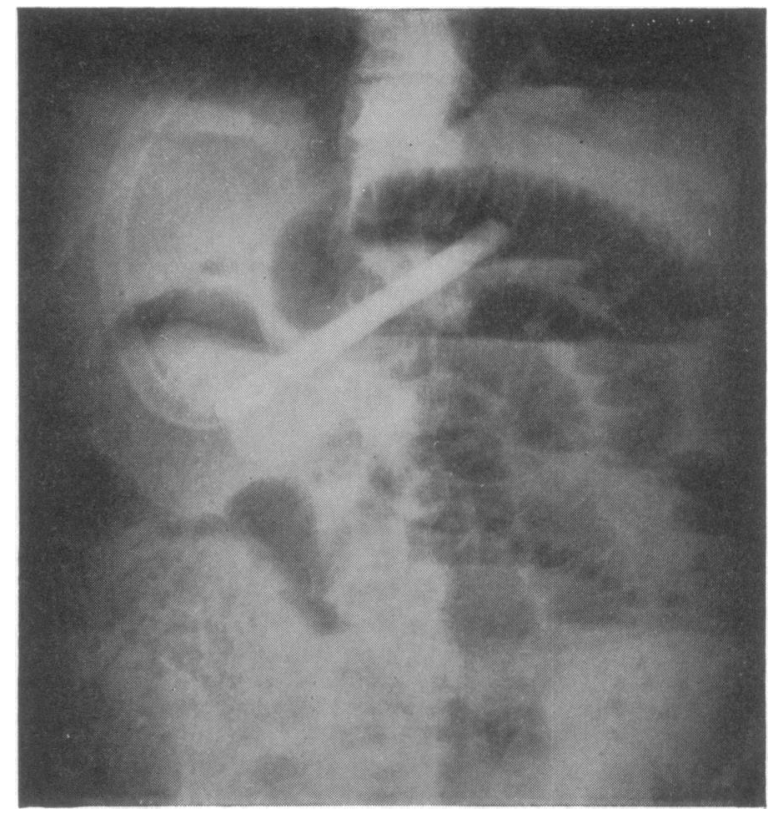

Fig. 3 
apparently had 47 chromosomes; the extra one was either almost telocentric or else was an acentric fragment. This cell could possibly be a normal one in which the long arm of a $C$ group chromosome has been broken and the fragment displaced. The third cell, with 45 chromosomes, appeared to have an extra B group chromosome and to be lacking two in the G group; the last cell, with 46 chromosomes, was difficult to fit to a normal karyotype but cannot be called definitely abnormal.

\section{Case 9}

A 4-parous woman aged 43, one and half years post-menopausal, complained of post-coital bleeding. The cervix did not appear clinically suspicious of malignancy, but abnormal cells were found in the cervical smear, and a biopsy was performed on 4 March 1964. This showed characteristic appearances of carcinoma-in-situ. A subsequent hysterectomy specimen showed no evidence of invasion or of carcinoma-in-situ, but still showed abnormal epithelium regarded as dysplastic (Special Plate, Fig. 4). A sample of this material was used for the chromosome preparations.

Only seven metaphases were considered good enough for counting, and three of these had 46 chromosomes. Cut-out karyotypes were made from five cells. Two of these showed no abnormality; the other three were clearly abnormal, and although chromosome morphology was too poor for a complete analysis they all showed a long marker chromosome. Another cell, not well enough spread for counting, also showed this marker, and the four are reproduced together in Fig. V. Each of these chromosomes was the longest in its set, and the constriction present in the long arm strongly suggests that this is the site of a translocation.

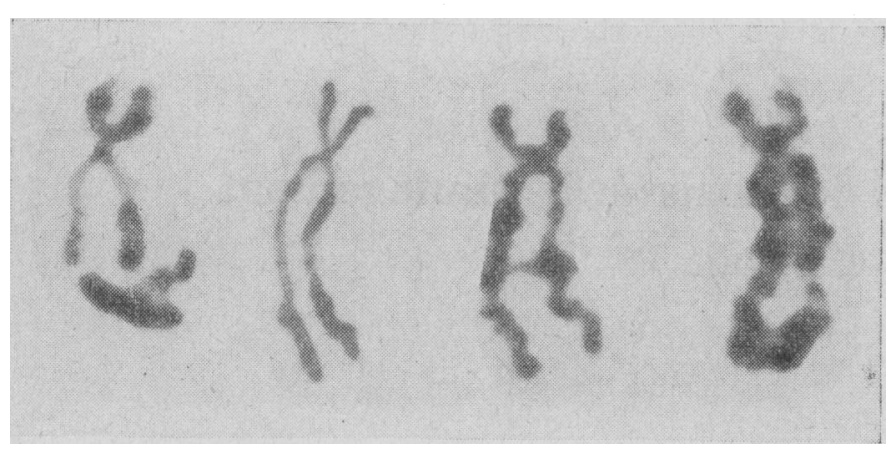

FIG. V.-Case 9. Four of the long marker chromosomes, taken from four different cells. Each was the longest chromosome in its set.

\section{Discussion}

Primary carcinomas of man, in the cases so far described, have consisted of populations of cells with grossly abnormal karyotypes. There is very good evidence that these are new clones, as the cells from the same tumour possess distinctive chromosomal abnormalities in common which indicate their common origin (Wakonig-Vaartaja, 1962, 1963; Spriggs, Boddington, and Clarke, 1962b; Lubs and Clark, 1963; Spriggs, 1964). These clones are unique, each having its own abnormal karyotype pattern. Primary carcinomas therefore show the same kind of cytogenetic abnormalities as do "ascites tumours" of carcinomatous origin.

Makino, Ishihara, and Tonomura (1959) published a series of observations on the chromosomes of 30 human neoplasms. Among them was a case referred to as Bowen's disease of the vagina-that is, carcinoma-in-situ. Biopsy material from this lesion produced 25 countable metaphases, showing a wide scatter of values from 54 to 116 , the most frequent values being around 56-59. Since a scatter of chromosome counts with an aneuploid modal value was also found in the invasive carcinomas in this series it appears that the same kind of chromosomal anomaly is already present at a precancerous stage.

Several years ago it was suggested on morphological grounds that the altered cells found in cervical smears from cases of carcinoma-in-situ and related dysplasias might represent new clones which persist unaltered for considerable periods of time (Boddington, Cowdell, and Spriggs, 1960). With this idea in mind we began to examine the chromosomes in biopsy specimens from these lesions. It now appears that the situation is a complex one, and the data by no means support the concept of a whole area of abnormal epithelium with a single new and consistent stemline. There is often a wide variation in chromosome number, which admittedly is in some degree due to cell breakage during preparation, but in our opinion is in large part genuine. There is, however, evidence of the development of new clones. In the first place, there are groups of cells with the same or similar abnormal chromosome counts, and these are particularly obvious in Cases 1,3 , and 7 in the present series, and in Case 6 of the previous series (Spriggs et al., 1962a) (two out of these four cases showed invasion in further biopsy samples). Secondly, there are groups of cells carrying a marker chromosome in common. This was noted in Case 9 of this series, and in Cases 5 and 6 of the previous series (both of which were subsequently found to be associated with early invasion). However, obvious structural abnormalities of the chromosomes are absent in most cases, and it seems likely that mitotic non-disjunction and lagging play a larger part than chromosome breakage in producing these abnormal cell populations.

Richart and Corfman (1964) have found normal karyotypes in cells cultured from carcinomas-in-situ. This may be explained by the selective effect of culture. That cells with apparently normal karyotypes are dividing already in vivo along with abnormal ones is demonstrated by our Cases 8 and 9 . It is impossible to decide whether these contribute to the abnormal epithelium or not.

It is unfortunate that the stability of the karyotype in chronic inflammation and in regenerating cervical epithelium has not yet been demonstrated. The mitotic rate is usually too low to provide adequate preparations with present techniques, and we have so far failed to find any well-spread metaphases in control samples; nor do there seem to be any relevant descriptions in the literature. There are a few microspectrophotometric data on the D.N.A. of the nuclei of normal and abnormal cervical epithelium (Reid and Singh, 1960 ; Grundmann, Hillemanns, and Rha, 1961 ; Sandritter and Fischer, 1961 ; Laumonier, Laquerrière, Nobecourt, and Hemet, 1963) and these are mainly consistent with the accepted view that non-neoplastic epithelium is diploid (though this has not been proved) and that carcinomain-situ and invasive cancer both show high values with abnormal scatter. Steele, Manocha, and Stich (1963) published some observations on 12 cases of carcinoma-in-situ, showing variable high D.N.A. values in every case ; but the comparison was made with normal skin and not with infected or healing cervix uteri, so that a clear distinction between benign and neoplastic epithelium is still not established.

It is tempting to equate carcinoma-in-situ with the stage of chromosomal heterogeneity in the livers of rats treated with liver carcinogens, before and during the development of a distinct stemline (Stich, 1960). It has to be remembered that carcinomain-situ has a long life, and the cases discovered are likely to have had their lesions already for a number of years, during which there has been continuous cellular turnover with desquamation at the surface. The analogy between this and a chemically damaged liver cannot be very close, but the comparison is still a suggestive one. In neither case can we think of carcinoma in terms of only a few mutated genes, coding for a few proteins which are concerned with the regulation of growth and differentiation. There is more probably a derangement of balance in the karyotype as a whole (Hauschka, 1963) with progressive adaptation under the influence of selective forces, long before the onset of malignancy. Apparently the abnormal cervical epithelium remains for years under partial control, surviving many vicissitudes (chronic inflammation, parturition), and at last in a proportion of cases gives rise to a "successful " variant which chances to have the capacity to invade. 


\section{Summary}

The chromosomes were examined in preparations made directly (without culture) from biopsy material from the affected area in eight cases with presumptive precancerous change (carcinoma-in-situ or dysplasia) of the cervix uteri and one of the vagina. The eight cervical lesions were entirely intraepithelial, but the vaginal one was associated with a small invasive carcinoma.

In every case there were variations in the chromosome count, sometimes with abnormal modal values suggesting new clone formation. In most of those cells in which karyotype analysis could be performed there was an abnormal distribution in the Patau groups with little evidence of structural changes. In one case an abnormal clone of cells was identifiable by a long marker chromosome.

It is concluded that extensive chromosomal rearrangements and adaptations are taking place in precancerous epithelium, often for years before the onset of carcinoma.

We wish to thank our colleagues who have supplied us with the biopsy material: Professor J. Chassar Moir, Mr. J. A. Stallworthy, Mr. W. Hawksworth, Mr. M. P. Embrey, Mr. K. V. Cooper, and Dr. P. F. Giles, in the United Oxford Hospitals ; Mr. C. J. Champ, at Amersham General Hospital ; and Mr. D. N. S. Robertson and Mr. E. G. G. Jonas, at Stoke Mandeville Hospital, Aylesbury. We are also indebted to the pathologists who have supplied us with sections: Dr. R. H. Cowdell, Dr. M. S. Dunnill, Dr. W. C. D. Richards, Dr. W. A. Aherne, Dr. H. J. Harris, and Dr. C. R. Tribe. We acknowledge with thanks the photographic assistance of Dr. T. Parry and Mr. R. L. Wilkins, and the technical assistance of Mrs. T. Wilkins, Mrs. M. Ayres, and Mrs. B. M. Allardyce. Two of us (M. M. B. and A. I. S.) were supported by the British Empire Cancer Campaign.

\section{REFERENCES}

Boddington, M. M., Cowdell, R. H., and Spriggs, A. I. (1960). Brit. F. Cancer, 14, 151

Grundmann, E., Hillemanns, H. G., and Rha, K. (1961). Z. Krebsforsch., $64,390$.

Hauschka, T. S. (1963). Exp. Cell Res., Suppl. No. 9, p. 86.

International Committee on Histological Terminology for Lesions of the Uterine Cervix ; Report on Proceedings (1961). Proceedings of First International Congress of Exfoliative Cytology, Vienna, p. 283.

Laumonier, R., Laquerrière, R., Nobecourt, J., and Hemet, J. (1963). Ann. Anat. path., 8, 275 .

Lubs, H. A., and Clark, R. (1963). New Engl. F. Med., 268, 907.

Makino, S., Ishihara, T., and Tonomura, A. (1959). Z.' Krebsforsch., 63, 184.

Reid, B. L., and Singh, S. (1960). F. nat. Cancer Inst., 25, 1291.

Richart, R.' M., and Corfman, P. A. (1964). Science, 144, 65.

Sandritter W. and Fischer, R. (1961). Proceedings of First Inter national Congress of Exfoliative Cytology, Vienna, p. 189.

Spriggs, A. I. (1964). Brit. F. Radiol., 37, 210. Spriggs, A. I. (1964). Brit. F. Radiol., 37, M. (1962a). Lancet, 1, 1383.

Steele, H. D., Manocha, S. L., med. F., 2, 1431. (1962b). Ibid., 2, 1314.

Stich, H. F. (1960). I. nat. Cancer Inst., 24, 1283.

Wakonig-Vaartaja, R. (1962). Brit. F. Cancer, 16, 616.

- (1963). Aust. N.Z. F. Obstet. Gynaec., 3, 170.

\title{
Role of the Ankle-jerk in the Diagnosis and Management of Thyroid Disease
}

\author{
D. W. MILES,* M.B., CH.B., B.SC. ; I. SURVEYOR, † M.B., M.R.C.P.
}

Brit. med. F., 1965, 1, 158-161

Changes in the time of contraction and relaxation of the anklejerk in thyroid disease have been claimed to be of diagnostic importance (Lambert et al., 1951 ; Lawson, 1958 ; Fogel et al., 1962 ; Sherman et al., 1963). There is still some dispute on whether the phase of contraction of the muscle is altered or whether the changes observed occur only during the relaxation phase. Fogel et al. (1962) reported that the "musclecontraction phase occurs promptly regardless of the thyroid state of the individual." Sherman et al. (1963) were unable to confirm this.

Previous studies on the usefulness of the ankle-jerk have been made on patients in whom the clinical diagnosis was beyond dispute (Lawson, 1958 ; Sherman et al., 1963). The present work was undertaken to assess the value of timing the anklejerk as a diagnostic test in doubtful as well as in definite disturbances of thyroid function.

Comparisons are made between the jerk times, clinical assessment, and radioactive-iodine uptake.

The measurements of jerk times during the treatment of patients with myxoedema and thyrotoxicosis are illustrated and the value of this test in their management is discussed. Changes in the jerk times in panhypopituitarism after the use of thyroidstimulating hormone and in normal subjects after the administration of large doses of triiodothyronine are also reported.

\footnotetext{
* Registrar, Department of Medicine, the University of Leeds. + Registrar, Department of Nuclear Medicine, the General Infirmary at Leeds.
}

\section{Subjects}

The 131 normal subjects studied were composed of volunteers from the hospital staff and patients suffering from minor trauma who attended the casualty department. One normal subject was rejected because satisfactory recordings were not obtained. Two patients with unsatisfactory ankle-jerks were rejected from this study.

Twenty-eight men and 137 women aged from 14 to 71 years (Table I) were referred for assessment and radioactive-iodine uptake. These included 21 patients previously treated with radioactive iodine, eight treated by partial thyroidectomy, and three treated by both surgery and radioactive iodine.

TABLE I.-Age and Sex Distribution of the 165 Patients Referred for

\begin{tabular}{|c|c|c|c|c|c|c|c|c|}
\hline Age: & $10-19$ & $20-29$ & $30-39$ & $40-49$ & $50-59$ & $60-69$ & $70+$ & Total \\
\hline 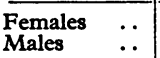 & $\begin{array}{l}6 \\
0\end{array}$ & $\begin{array}{r}14 \\
3\end{array}$ & 24 & $\begin{array}{r}29 \\
7\end{array}$ & $\begin{array}{r}43 \\
7\end{array}$ & $\begin{array}{r}18 \\
8\end{array}$ & $\begin{array}{l}3 \\
0\end{array}$ & $\begin{array}{r}137 \\
28\end{array}$ \\
\hline
\end{tabular}

\section{Methods}

The patients were graded clinically and placed in the following groups: (1) probably thyrotoxic ; (2) possibly thyrotoxic ; (3) probably normal ; (4) possibly hypothyroid ; and (5) probably hypothyroid. 